\title{
从地表辐射平衡、热具平衡论 青藏高原的热力作用
}

\author{
曾群柱谢应钦 \\ (中国科学院兰州冰川陈土研究所)
}

\section{一、篮高原辐讨平衡状况}

根据我们对高原辐射平衡 ( $B$, 下同)的研究 ${ }^{[13}, B$ 分布的总趋势自西南向东北减少. 全区 $B$ 的年总量介于 60.0-80.0 千卡/厘米之之间. 高值区位于葛尔、班戈、那曲、日喀则至定日一 带, 年总量大于 80.0 干卡/厘米 2 (图 1). 此高值区终年存在, 6 月范围最大, 向北扩展到唐古 拉山以北; 12 月最小,收缩到日喀则、定日一线; 零值线位于喀什、和田、若芫沿阿尔金山北麓, 经敦煌至酒泉一带(图 2). 因此, 高原 $B$ 值全年为正; 只有在海拔 5000 米以上终年为冰雪覆 盖的地区才有可能为负值. 例如, 珠穆朗玛峰东线布冰川粒雪盆 (6325.0 米) $B$ 的年总量为 -1.80 千卡/臣米 ${ }^{2221}$, 这是青藏高原 $B$ 分布的一个很重要的特点.

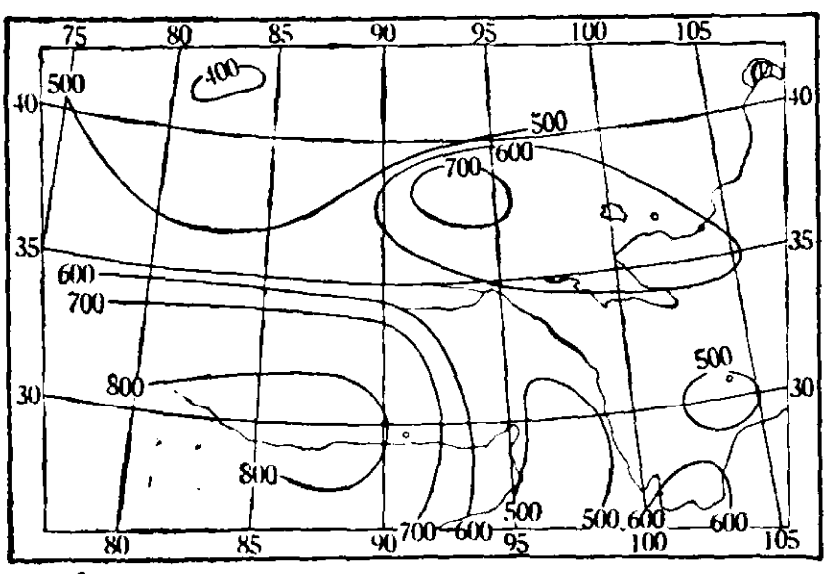

图 1 薄藏高原 $B$ 年总量分布图 (千卡/厘米 ${ }^{2}$ )

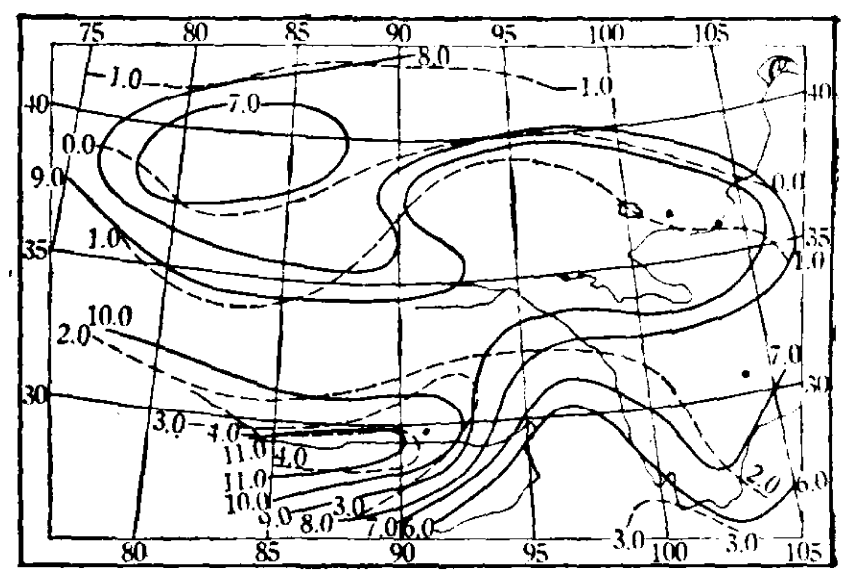

图 2 青藏高原 6 月和 12 月 $B$ 分布图 (千卡/厘米 ${ }^{2}$ )

-6 月, …1 12 月

\section{二、晋藏高原地表热量平衡及其组成}

地表热量平衡方程为

$$
B=P+E L+A,
$$

式中 $B, P 、 E L$ 和 $A$ 分别为辐射平衡、湍流热交换、蒸发耗热或凝结释热以及土壤热交换，均 
以卡/厘米 ${ }^{2}$ 分计.

对高原中部土门格拉(海拔 4930.5 米, 北纬 $32^{\circ} 51^{\prime}$ ，东经 $91^{\circ} 18^{\prime}$ ) 1965 年地表热量平衡资 料分析得知, 在 $B$ 的年总量中有 $98.8 \%$ 的热量通过湍流交换以感热和潜热的形式冕散于大气 之中，用于土壤增温和冻土融化的热量仅占 $1.2 \%$ (表 1). 如取高原 $B$ 年总量的下限 60.0 干 卡/厘米 ${ }^{2}$ 计算,青藏高原全年每平方公里向大气输送的热量约 $59.28 \times 10^{10}$ 千卡. 这就是为什 么在高原 $\boldsymbol{B}$ 值(年或月)很大的情况下仍能发育大面积多年冻土的主要原因.

表 1 青藏高原土门格拉地区 1965 年地表热量平衡及其组成 (\%)

\begin{tabular}{|c|c|c|c|c|c|c|}
\hline \multicolumn{2}{|c|}{ 项 } & 收 & $\lambda$ & & & \\
\hline 月 & & \multirow{2}{*}{$B$} & \multicolumn{2}{|c|}{$A$} & \multirow{2}{*}{$E L$} & \multirow{2}{*}{$\boldsymbol{P}$} \\
\hline \multicolumn{2}{|c|}{ 分 } & & 收 $\quad$ 人 & 支出 & & \\
\hline & 10 & 97.5 & 2.5 & & -22.6 & -77.4 \\
\hline & 11 & 80.3 & 19.7 & & -23.0 & -77.0 \\
\hline & 12 & 78.9 & 21.1 & & -12.9 & -87.1 \\
\hline & 1 & 70.1 & 29.9 & & -25.4 & -74.6 \\
\hline & 2 & 85.1 & 14.9 & & -21.5 & -78.5 \\
\hline & 3 & 95.1 & 4.9 & & -28.6 & -71.4 \\
\hline & 4 & 100.0 & & -4.1 & -17.1 & -78.9 \\
\hline & 5 & 100.0 & & -8.6 & -14.3 & -77.1 \\
\hline & 6 & 100.0 & & -16.1 & -29.0 & -54.9 \\
\hline & 7 & 100.0 & & -20.6 & -36.1 & -44.3 \\
\hline & 8 & 100.0 & & -16.5 & -28.4 & -55.1 \\
\hline & 9 & 100.0 & & -7.3 & -18.1 & -74.6 \\
\hline \multirow{2}{*}{ 年平均 } & 按月总㽬计算 & 92.2 & 7.8 & -6.1 & -23.1 & -70.8 \\
\hline & 按年总量计算 & 100.0 & & -1.2 & -23.8 & -75.0 \\
\hline \multirow{2}{*}{\multicolumn{2}{|c|}{$\begin{array}{l}\text { 夏半年 }(4-9 \text { 月) } \\
\text { 冬半年 }(10-3 \text { 月) }\end{array}$}} & 100.0 & & -12.2 & -23.8 & -64.0 \\
\hline & & 84.5 & 15.5 & & -22.3 & -77.7 \\
\hline
\end{tabular}

由表 1 还可以看出，全年各月的热量平衡组成有较大的差异。在夏半年 (4-9 月) $B$ 总 量中，除了 $12.2 \%$ 耗于冻土融化和土壤增温以外, $87.8 \%$ 的热量以感热和潜热的形式向大气 输送. 若夏半年 $B$ 平均取 9.0 千卡/厘米 ${ }^{2}$.月,则整个夏半年高原每平方公里约有 $47.41 \times 10^{10}$ 干卡的热量加热大气. 加热最强的葛尔、班戈、那曲、拉萨、日喀则和定日带, 在加热最剧烈的 5 月份 ( $B$ 为 11.0 干卡/厘米 ${ }^{2}$ 月), 全月每平方公里向大气输送约 $10.1 \times 10^{10}$ 千卡的热量, 为全年最大. 这些热量通过对流源源不断地向更高层大气输送, 是维持青藏高原夏半年地面 热低压, 高空暖高压系统的主要动力.

Flohn ${ }^{[3]}$ 认为,夏半年高原存在东、西两个加热中心,前者主要为潜热，后者为感热。我们 分析高原 $B$ 值与地表热量平衡状况得知, 夏半年高原西部加热中心感热 (占 $64 \%$ ) 和潜热 (占 $23.8 \%$ ) 兼而有之.

冬半年 (10-3 月),在昆仑山、阿尔金山以南,高原各月的 $B$ 值均为正(图 2), 同时由于气 温低,高原多数地区的地表面处于冻结状态,地表从土壤中获得热量. 土门格拉整个冬半年地 表从土壤中获得的热量约 $2.81 \times 10^{10}$ 千卡/公里 ${ }^{2}$, 占地表热量收入的 $15.5 \%$; 辐射平衡热量 约 $11.87 \times 10^{10}$ 千卡/公里 ${ }^{2}$,占地表热量收人的 $84.5 \%$ ．两者总和的 $77.7 \%$ 以感热， $22.3 \%$ 以 
潜热的形式逸散于大气. 因此，冬半年高原地表对大气的加热以感热为主。

\section{三、帮藏离原各地的气一地温差}

青藏高原以其高大的地形箃立于自由大气之中,风速大、气温低,但太阳直接辐射强,地面 吸收辐射(即短波辐射平衡)大,地表面温度高. 根据实测资料统计, 高原绝大多数台站年及各 月平均气温与地表温度之差均为负值 (表 2), 热流方向自地表面指向大气.

表 2 青藏商原主要气象台站多年平均气一地温差统计表(单位: “' )

\begin{tabular}{|c|c|c|c|c|c|c|c|c|c|c|c|c|c|}
\hline & 1 & 2 & 3 & 4 & 5 & 6 & 7 & 8 & 9 & 10 & 11 & 12 & 年 \\
\hline 五进梁 & 0.0 & -0.6 & -1.2 & -2.2 & -1.5 & -3.7 & -4.2 & -4.2 & -3.5 & -2.2 & -0.8 & -0.2 & -1.8 \\
\hline 沦沦河 & -0.1 & -0.6 & -1.5 & -2.8 & -3.4 & -4.1 & -4.6 & -4.5 & -3.9 & -2.4 & -0.9 & -0.2 & -2.4 \\
\hline 泟 車 & -0.5 & -0.5 & -1.4 & -2.4 & -3.0 & -3.9 & -4.5 & -4.3 & -3.7 & -2.6 & -1.4 & -2.0 & -2.5 \\
\hline 玛 多 & -0.1 & -0.5 & -1.5 & -2.4 & -3.2 & -3.7 & -4.2 & -4.1 & -3.5 & -2.3 & -1.0 & -0.1 & -2.2 \\
\hline 玉 树 & -0.6 & -1.3 & -2.9 & -3.9 & -5.2 & -4.6 & -4.1 & -3.8 & -2.7 & -1.9 & -1.7 & 0.0 & -2.8 \\
\hline 安 & 1.5 & -0.5 & -2.4 & -3.1 & -5.9 & -5.3 & -4.1 & -4.5 & -3.9 & -2.1 & -2.5 & -0.6 & -2.7 \\
\hline 尔 & -1.5 & -3.3 & -5.0 & -6.5 & -8.1 & -8.8 & -8.1 & -7.0 & -5.5 & -3.5 & -1.5 & -0.9 & -5.0 \\
\hline 索 & -0.4 & -1.2 & -2.4 & -3.3 & -4.2 & -4.0 & -4.7 & -4.5 & -3.6 & -2.8 & -1.4 & 0.1 & -2.8 \\
\hline 那 & -1.8 & -3.0 & -3.9 & -5.3 & -5.7 & -5.8 & -6.2 & -5.3 & -5.2 & -4.8 & -3.0 & -1.5 & -4.3 \\
\hline 丁 & -1.3 & -2.2 & -3.4 & -4.7 & -5.2 & -5.0 & -5.6 & -4.8 & -3.3 & -2.5 & -1.2 & -0.6 & -3.4 \\
\hline 日喀则 & -0.7 & -2.1 & -4.0 & -6.0 & -7.2 & -8.0 & -6.1 & -5.1 & -5.0 & -3.8 & -1.6 & -0.2 & -4.1 \\
\hline 拉 萨 & -1.1 & -1.9 & -3.7 & -5.0 & -5.9 & -5.9 & -4.0 & -3.9 & -3.0 & -1.6 & -1.2 & -1.1 & -3.1 \\
\hline 江 & -0.8 & -1.8 & -3.8 & -5.0 & -6.4 & -7.3 & -7.2 & -5.3 & -5.1 & -3.5 & -1.3 & -0.2 & -4.0 \\
\hline 昌 & -1.1 & -2.0 & -3.0 & -4.6 & -5.0 & -3.7 & -4.5 & -4.5 & -3.7 & -3.6 & -1.9 & -1.0 & -3.2 \\
\hline 改 & 0.0 & -0.9 & -2.3 & -4.2 & -5.9 & -6.4 & -5.2 & -4.5 & -3.5 & -1.8 & -0.5 & 0.1 & -2.7 \\
\hline 平均 & -0.5 & -1.5 & -2.8 & -4.1 & -5.1 & -5.3 & -5.2 & -4.7 & -3.9 & -2.8 & -1.5 & -0.6 & -3.1 \\
\hline
\end{tabular}

由表 2 可知, 年平均气一地温差绝对最大值位于葛尔、那曲、拉萨至江孜、日喀则一带,与 $B$ 年总量的高值区相吻合. 就全年各月而论,气一地温差绝对最大值出现在 6 月,最小为 12 月和 1 月,与 $B$ 的最大和最小值出现的月份亦基本一致.

综上所述,如果按文献 [4] 关于冷、热源的定义, 那么冬半年的青藏高原地面无疑是一个 热源. 只不过由于冬半年的 $B$ 值只有夏半年的 $1 / 3-1 / 4$, 因而向大气供热的强度较弱; 同时 冬半年整个青藏高原为东亚副热带西风急流所控制，气温低、风速大，加热不容易集中; 不仅如 此, 相对来说，高原加热不如四周平原大，致使冬半年高原地表面对大气的热力作用表现不十 分明显,但并不能因此而改变它作为热源的实质。

所以,将冬半年的青藏高原地面一概视为冷源是不恰当的,充其量在海拔 5000 米以上 且 冬半年 $B$ 值为负的冰雪地带才有可能成为热汇.

致谢: 本文承高由福教授审阅，并提出宝贵意见，谨致衷心感谢。

[1] 曾群柱、宽有观、谢维荣、肖钦，中国科学院兰州冰川冻土研究所集刊第二号(即将出版).

[2] 完有观、曾群柱、谢维荣、谢应软, 珠稳朗玛地区科学考察报告 (1966-1968), 科学出版社, 1975, 118一-132.

[3] Flohn, H., Atm. Sci. Paper, Colorado State University, 1968, 130: 1-20.

[4] 叶等正、罗四维、朱抱真,气象学报, 28 (1957), 2: 108-121. 